\title{
Organizações \& Sociedade: sobrevivência e consolidação de um periódico científico no Brasil
}

\author{
José ANTONIO GOMES DE PINHO' \\ SANDRO CABRAL ${ }^{12}$ \\ ARIÁDNE SCALFONI RIGO' \\ ${ }^{1}$ Universidade Federal da BAHIA (UFBA) / Escola de AdMINISTRAÇÃO, SALVAdor - BA, Brasil \\ 2 INSTITUTO DE ENSINO E PESQUISA (INSPER), SÃo PAULO - SP, BRASIL
}

\section{Resumo}

O presente texto analisa a trajetória e as perspectivas da revista Organizações \& Sociedade (O\&S). Único periódico científico da área de Administração situado nos estratos mais altos do Qualis-CAPES de responsabilidade de uma universidade pública federal, a O\&S consolidou-se como um veículo plural que prima pelo rigor e relevância dos trabalhos publicados.

Palavras-chave: Pesquisa em administração. Periódicos. Processo editorial. Organizações.

\section{Journal Organizações \& Sociedade: survival and consolidation of a scientific journal in Brazil}

\section{Abstract}

This work analyzes the history and the perspectives of journal Organizações \& Sociedade (O\&S). O\&S is the only management journal that has the highest ranking of the Qualis-CAPES index published by a public federal university in Brazil. O\&S is widely known as a plural journal and for the rigor and the relevance of the published articles.

Keywords: Management research. Scientific journals. Editorial process. Organizations.

\section{Organizações \& Sociedade: supervivencia y consolidación de un periódico científico en Brasil}

\section{Resumen}

El presente trabajo analiza la trayectoria y las perspectivas de la Revista Organizações \& Sociedade (O\&S). O\&S es el único periódico científico del campo de Administración publicado por una universidad pública federal brasileña situado en las más altas posiciones del índice QualisCAPES. O\&S es conocida por ser una revista plural y por el rigor y la relevancia de los trabajos que publica.

Palabras clave: Investigación en gestión. Revistas científicas. Proceso editorial. Organizaciones. 


\section{ORIGEM E PROPOSTA DA O\&S}

A revista Organizações \& Sociedade (O\&S) foi publicada pela primeira vez em dezembro de 1993. Em 2018, ao completar 25 anos, é possível olharmos em perspectiva sua história, suas conquistas, seus percalços e projetar seus desafios - muitos dos quais são comuns aos demais periódicos no Brasil e, especificamente, os da área de Administração.

Quando a O\&S foi lançada, a área de Administração contava apenas com 4 periódicos:

a) Revista do Serviço Público - desde 1937 -, na área do Governo Federal;

b) Revista de Administração Pública (RAP) - desde 1967-, da Escola Brasileira de Administração Pública e de Empresas da Fundação Getulio Vargas (FGV EBAPE);

c) Revista de Administração de Empresas (RAE) - desde 1961 -, da Escola de Administração de Empresas de São Paulo (FGV EAESP); e

d) Revista de Administração (RAUSP), da Faculdade de Economia, Administração e Contabilidade da Universidade de São Paulo (FEA-USP) - desde 1947.

Assim, a O\&S juntava-se a esse seleto e pequeno grupo de periódicos já consolidados, para reforçar a veiculação da produção acadêmica em Administração no Brasil.

O lançamento da O\&S, em 1993, pode ser visto como um marco no conjunto de periódicos do campo no país por duas razões principais. Primeiro, a O\&S foi a primeira revista da área de Administração criada por e dentro de uma universidade federal e, mais que isso, no Nordeste do país. Segundo, a revista ousou ao definir seu escopo para além da Administração, tanto que seus criadores optaram por um nome mais aberto a publicações de outras áreas do conhecimento. Organizações, de fato, é um tema mais abrangente do que Administração e Sociedade indica que a pesquisa sobre as organizações ocorre dentro de um contexto multifacetado. Assim, a revista procurou absorver estudos e resultados de pesquisa vindos de um universo mais amplo e diversificado. Havia consciência da abrangência e da pretensão que a revista ensejava, indicando claramente a importância das organizações na vida contemporânea.

\section{SOBREVIVÊNCIA E DESAFIOS}

Os primeiros anos foram muito difíceis. A revista surgiu de um movimento de forças dentro da Escola de Administração da Universidade Federal da Bahia (EAUFBA), com o suporte de professores de outras instituições de ensino no Conselho Editorial. Merece registro a capacidade visionária de seu primeiro Editor e um dos fundadores, Professor Maurício Serva, que empreendeu esforços, junto com outros professores da EAUFBA, para viabilizar o empreendimento de grande monta que era lançar uma revista "apesar das sérias adversidades pelas quais passa a universidade brasileira" (SERVA, 1993, p. 5), nas palavras do próprio Editor logo no primeiro editorial.

As dificuldades dos anos iniciais continuaram sendo expressas nos editoriais dos números subsequentes. Além de expressar as dificuldades, seus primeiros Editores reforçaram o caráter aberto e multidisciplinar da revista. A O\&S era semestral, algo comum naquela época. O número 2 foi apresentado pelo então Diretor da EAUFBA, Professor Reginaldo Souza Santos, em 1994, que se desculpou pelo atraso da publicação devido à falta de recursos, ao mesmo tempo que manifestou o objetivo daquela edição: apresentar temas que refletissem as inquietudes das organizações contemporâneas. O número 3 foi apresentado pelo Professor Genauto Carvalho de França Filho (Subeditor da revista e Editor-Chefe dos números 5 e 6), que expressou "mais uma vez a importância de enfoques multidisciplinares para a compreensão do fenômeno organizacional", deixando claro o enfoque multidisciplinar, que viria a ser uma das características marcantes da O\&S. Na edição 4, em 1995, França Filho (1995, p. 5) destacou, novamente, os "enfoques interdisciplinares" afirmando, em seguida, a "esperança de estarmos contribuindo para a construção de um novo caminho na direção de uma compreensão aprofundada da sociedade das organizações".

No número 7, publicado no segundo semestre de 1996, ocorreram duas importantes mudanças. A primeira foi a mudança de Editor, assumindo o Professor José Antonio Gomes de Pinho, que permaneceu na posição até 2013. A segunda mudança foi a periodicidade da revista, que passou a ser quadrimestral. Em seu primeiro editorial, Pinho $(1996$, p. 6) reafirmou a posição da revista como "veículo para a circulação da produção acadêmica proveniente de pesquisadores de várias instituições que 
trafegam na área de organizações e sociedade", manifestando preocupação com a nascente questão da endogenia, um mal que afetava (e ainda afeta) a credibilidade de muitas publicações acadêmicas no Brasil, ao priorizarem artigos de professores da instituição hospedeira do periódico.

Na apresentação do número 9, o então Editor entendia que as publicações veiculadas refletiam as melhores produções do país, destacando também que os artigos publicados ofereciam uma boa visão da produção acadêmica na área de Administração. Mais uma vez, a pluralidade de temas e enfoques era reafirmada, tornando-se a marca da revista.

A pluralidade é uma característica indelével da O\&S, a qual, desde sua primeira publicação, posiciona-se como "veículo para a circulação da produção acadêmica proveniente de pesquisadores de várias instituições que trafegam na área de organizações e sociedade" (PINHO, 1996, p. 6). Em outras palavras, a revista não seria local ou regional, mas da comunidade nacional como um todo e mesmo da comunidade internacional, como já ocorria por meio de contribuições de autores de renome, tais como Jean-François Chanlat, em uma época em que ainda não havia a preocupação com a internacionalização dos periódicos.

De qualquer modo, as dificuldades se mantinham, pois, era estoico o trabalho de afirmar a revista no contexto nacional, em termos práticos, atrair artigos de pesquisadores e instituições de renome. É necessário situar o leitor que não havia naquela época a "febre" de publicação que existe mais contemporaneamente. Assim, a comunidade não estava tão mobilizada para a publicação. Em outros termos, o editor tinha de "correr atrás" de artigos para fechar uma edição. Nesses anos iniciais, a revista contou com a colaboração expressa de pesquisadores nacionais de renome, que aportavam seus artigos à nova publicação que surgia, certamente imbuídos da confiança no futuro do empreendimento e de um espírito de solidariedade com a emergente revista. Sem esgotar os nomes (de fora da Universidade Federal da Bahia - UFBA) que contribuíram, vale o registro de Clóvis Machado-da-Silva, Anna Maria Campos, Breno Souto Maior, Paulo Zawislak e Norma Lacerda.

Neste ponto, cabe uma digressão oportuna. As revistas da época (mesmo de outras áreas) apresentavam um pequeno número de artigos (5 ou 6), fruto da produção científica incipiente no campo da Administração. Para ter uma ideia, o Encontro da Associação Nacional de Pós-Graduação e Pesquisa em Administração (EnANPAD) publicou 131 artigos em seus Anais em 1989, 116 em 1990, 204 em 1991, 143 em 1992, 190 em 1993 e 215 artigos em 1994. Se o maior evento na área de Administração do país, comparado aos dias de hoje, recebia e publicava um baixo número de artigos, o que dizer de um periódico recentemente criado no Nordeste do Brasil? No entanto, mesmo nesse contexto e com essas adversidades, a revista exibia uma característica que permanece: ser aberta aos interesses dos pesquisadores de modo geral, evitando privilegiar pesquisadores de sua instituição de abrigo.

A partir do número 9, podemos dizer que a revista ganhou uma gerência mais profissional, com a entrada de uma secretária exclusiva para tratar de seus afazeres, Maria Candida Bahia, que permaneceu responsável por esse trabalho por muitos anos. A partir do número 15, a revista assumiu outro design, mantido até 2018 , mudando sua concepção gráfica e seu tamanho, passando a comportar maior número de artigos, o que confirmava que já havia se afirmado e podia assumir o compromisso de publicar mais artigos do que o que vinha fazendo. Nessa linha, a partir de 2005 a revista passou a ter periodicidade trimestral, um novo passo no sentido de publicar maior número de artigos, bem como ampliar sua visibilidade, passo este que sinalizava confiança nos objetivos do periódico por parte da comunidade acadêmica. O projeto gráfico da O\&S constitui um capítulo à parte. A revista não pode ser apreciada em sua inteireza sem mencionar as capas que marcaram sua imagem - todas, até hoje, de um apuro estético ímpar.

Até aqui, falamos da revista muito do ponto de vista de sua formatação, dos objetivos mais gerais e das dificuldades de estabelecer-se como uma referência na área. Uma pergunta válida é: quando a O\&S assume o perfil de conteúdo que tem? Para chegar a uma resposta mais acurada, possivelmente teríamos de fazer uma análise detalhada dos artigos publicados para que pudéssemos perceber algum tipo de tendência. De antemão, pode-se inferir que, por sua própria gênese, voltada ao abrigo de uma pluralidade de visões e temáticas, normalmente não ortodoxas e desvinculadas do que se entende como mainstream, dificultaria tal análise. No entanto, um exame mais minucioso da O\&S mostra seu caráter único e sem qualquer tipo de preconceitos temáticos, teóricos, metodológicos ou epistemológicos, à medida que, historicamente, tem comportado artigos dos mais variados matizes que compõem a vasta fauna da Administração no Brasil. A O\&S rompe paradigmas ao ter a necessária personalidade para veicular visões menos convencionais, bem como temas pouco usuais e não cobertos por outros periódicos. Dito de outro modo, os dois componentes de seu nome, Organizações e Sociedade, abarcam um amplo conjunto de temáticas, bastante aberto, que acolhe olhares menos convencionais sobre os fenômenos organizacionais, bem como sobre os movimentos da sociedade. 
Corroborando nosso entendimento, vamos nos socorrer na visão de um renomado e saudoso expoente da área de Administração no Brasil, o Professor Fernando Prestes Motta. No ano 2000, em evento realizado na EAUFBA, ele afirmou que a O\&S tem

[...] o perfil de revista de [A]dministração com que mais eu me afino. Eu acho que eu poderia contar algumas revistas, uma ou duas na Europa, uma ou duas nos Estados Unidos e essa no Brasil[,] que t[ê] m esse perfil, que é uma visão da organização como sistema social. Is[s]o está presente, inclusive, no nome (MOTTA, 2000, p. 16).

É oportuno ressaltar que, quando do falecimento do professor Prestes Motta, a revista publicou sua palestra (edição 26, de 2003). Personagens como ele fazem falta!

\section{CONSOLIDAÇÃO E ADMIRADORES}

Nesse mesmo ano de 2003, a revista completava 10 anos de existência, que foram comemorados com uma edição que trouxe contribuições dos componentes de seu Conselho Editorial. Nessa edição, o então Editor aproveitou para fazer um balanço dos artigos submetidos durante a década percorrida, uma espécie de "prestação de contas" à comunidade. Tal balanço representou uma contribuição não só aos autores e pareceristas da revista, mas uma espécie de guia para publicações emergentes. 0 Editor debruçava-se sobre os problemas mais recorrentes que os artigos apresentados continham quanto a seus objetivos, foco, referencial teórico, metodologia, a pesquisa propriamente dita e conclusões. Na linha de contribuição à comunidade de Administração, a revista também inovou quando seu Editor publicou o artigo "Brevíssimo manual do editor", onde expõe sua experiência acumulada transferindo, digamos assim, expertise para outros editores. Em um momento no qual novos periódicos começavam a surgir, a compilação de boas práticas e de reflexões acumuladas ao longo de anos serviram de referência a editores interessados em aprimorar seus processos e suas rotinas editoriais. Também serviu de guia para jovens autores interessados em conhecer a "cozinha" dos periódicos, de modo que pudessem preparar melhor seus manuscritos e suportar a longa espera entre o envio e o aceite. Mantendo seu caráter inovador e com impacto para além das fronteiras da área de Administração, a O\&S se destacou ao publicar um manuscrito inédito de João Ubaldo Ribeiro, ex-professor da EAUFBA nos anos 1960, desenvolvido quando de seu mestrado na University of Southern Califórnia, nos Estados Unidos da América (EUA). $O$ escrito de João Ubaldo, imortal da Academia Brasileira de Letras (ABL), foi publicado em 2 partes (edições 37 e 38, de 2006) e passeou pela questão das organizações já ensaiando uma visão crítica de adequação dos referenciais teóricos estadunidenses à realidade brasileira.

Assim como outros periódicos, a O\&S priorizou números temáticos abordando temas de interesse da sociedade. Nesse sentido, tornou-se clara a ênfase da revista no estudo de organizações, o que veio a se fortalecer ainda mais com o lançamento da edição especial sobre Alberto Guerreiro Ramos, nome que dispensa maiores apresentações no campo das organizações no Brasil, em uma edição co-organizada com o Professor Fernando Guilherme Tenório. Também vale destacar a edição referente ao Futebol, em 2009, organizada pelo Professor Sandro Cabral, que mostrava a já presente inclinação da O\&S por cobrir temas nada convencionais. Com tiragem de 500 exemplares, essa edição se esgotou rapidamente. Sua capa trazia uma seleção brasileira de todos os tempos, escalada pelos acadêmicos brasileiros da área de Administração com caricaturas genialmente desenhadas pelo artista Felipe Sancho. Na linha de que é possível, e necessário, alinhar trabalho e prazer, a O\&S lançou em 2013 um número especial sobre Organizações \& Carnaval, editada por Bernardo Buarque de Hollanda, cujo sobrenome não deixa dúvidas da importância do olhar refinado sobre um tema da mais suma importância para a construção da identidade brasileira.

Como dito, o renomado scholar Clóvis Machado-da-Silva tinha profunda ligação com a O\&S. Em 2010, ano de seu falecimento, a revista o homenageou, destacando que:

Ele sempre me dizia que havia tido uma participação ativa, junto com Maurício Serva, primeiro Editor da O\&S, na escolha do nome da revista [...] E dizia isso com muito orgulho [...] Também dizia que um dos seus desejos era ser editor da O\&S. Dizia isso sem qualquer constrangimento e, com muito bom humor, na minha presença. 
A produção de Clóvis veiculada na O\&S consiste em 10 artigos, e ele apostou tanto na revista que "publicou um artigo praticamente todo ano" (PINHO, 2010, p. 747).

Fruto dos esforços de todos os envolvidos, a O\&S teve inúmeras conquistas. Além do reconhecimento de muitos membros da comunidade, que não raro colocam a O\&S como a revista mais querida da área de Administração no Brasil, a creditação junto à SciELO e o reconhecimento oficial da Capes - que conferiu o conceito Qualis A2, estrato máximo ocupado por periódicos brasileiros da área de Administração - representam o reconhecimento da importância e da relevância da O\&S.

Com a demanda crescente, fruto de seu reconhecimento e das pressões por publicação em periódicos de ponta, naturalmente, a O\&S precisou reestruturar-se e uma série de transformações foi levada a termo. Adotando a linha dos periódicos internacionais de ponta, a O\&S implantou o sistema de desk review, no sentido de selecionar os artigos que seguem para avaliação dos pareceristas. Como qualquer editor bem sabe, revisores capazes de contribuir com a qualidade e com a responsividade necessária são recursos valiosos, raros e que devem ser protegidos como modo de proporcionar geração de valor tanto para os autores como para o periódico. É necessário alocar eficientemente a carga de trabalho de nossos abnegados pareceristas. Para tal, iniciou-se, ainda na gestão do Professor Pinho, um processo que se manteve ao longo da gestão da Professora Mônica Mac-Allister (2013) e da equipe de editores composta pelos professores Antônio Sérgio Araújo Fernandes, Ariádne Scalfoni Rigo e Sandro Cabral (abril de 2014 a dezembro de 2016), no qual editores e outros colaboradores ajudam nos processos editoriais de modo criterioso, dedicado e compromissado.

Nesse processo de mudança de patamar da O\&S, o início da submissão eletrônica foi fundamental, por meio da inserção da revista no Sistema de Editoração Eletrônica (SEER), entre 2013 e 2014. A partir desse período, a O\&S deu um salto em termos de organização de seus processos editoriais, buscando acompanhar os avanços e as inovações que surgiam no campo de editoração de periódicos no Brasil. Tais inovações possibilitaram a tomada de decisão no sentido de não mais imprimir as edições em meio físico e manter a revista totalmente gratuita e com acesso aberto ao seu conteúdo integral por meio de seu site.

Uma nova equipe editorial que assumiu a O\&S em abril de 2014 deu seguimento às sensíveis transformações iniciadas pela equipe anterior. Ações estratégicas, como a inserção da revista em outras bases de dados importantes; a aceleração dos processos de revisão por pares garantindo respostas mais rápidas aos autores; a busca incessante da pontualidade na publicação dos números; a criação da edição em inglês, para garantir a permanência na SciELO são apenas algumas ações que mostram como a O\&S busca, e tem conseguido, acompanhar as inovações das melhores revistas de Administração do Brasil.

Vale ressaltar um grande salto dado pela revista em termos de sua sustentabilidade nos últimos 4 anos. A busca por financiamento e acordos com parceiros importantes tem garantido a existência da revista e diminuído sensivelmente os custos de sua sustentação pelo programa de pós-graduação na EAUFBA. A aplicação de projetos em editais específicos para editoração de periódicos e o apoio de parceiros, como o Instituto Brasileiro de Estudos e Pesquisas Sociais (Ibepes), são ações empreendidas pela equipe editorial nesse sentido. De fato, com as dificuldades para captar recursos no âmbito do sistema federal de Ensino Superior, parcerias como essa são fundamentais para que a O\&S continue veiculando a boa produção em Administração no Brasil.

\section{A ORGANIZAÇÕES \& SOCIEDADE HOJE. E AMANHÃ?}

Seguindo a tendência de crescimento consistente, atualmente a O\&S recebe cerca de 400 submissões por ano, ou seja, mais de 1 artigo por dia chega para apreciação por parte da editoria da revista. Por meio da ampliação do corpo de revisores e de esforços para sensibilização a respeito da importância dos prazos de avaliação, a O\&S tem conseguido aliar qualidade dos pareceres a velocidade na resposta aos autores. Com uma taxa de aprovação em desk review de cerca de $30 \%$, atualmente a revista apresenta um fluxo editorial bastante enxuto, com uma média de 50 artigos no processo de avaliação e cerca de 32 artigos aprovados e em processo de editoração. Assim, os números correspondentes ao período de 1 ano já estão definidos, garantindo a pontualidade da publicação de seus números a cada trimestre. 0 Quadro 1 resume os prazos médios relativos aos processos editoriais da revista, os quais sinalizam aos autores que queiram veicular sua produção na O\&S a agilidade e a responsividade de seus processos editoriais, fruto dos esforços empreendidos pela comunidade da Administração brasileira como um todo. Trata-se, assim, de uma construção coletiva e abnegada dos pesquisadores e admiradores da revista, algo que nos enche de orgulho. 


\section{Quadro 1}

Prazos médios entre a submissão e a publicação de artigos na Organizações \& Sociedade

\begin{tabular}{|c|c|c|}
\cline { 2 - 3 } \multicolumn{1}{c|}{} & $2015-2016$ & 2017 \\
\hline Submissão e desk review & Até 15 dias & Até 15 dias \\
\hline Submissão e avaliações & 4,5 meses (média) -8 máx. & 4,5 meses (média) -8 máx. \\
\hline Submissão e aceitação & 9 meses (média) & 8 meses (média) - de 4 a12 meses \\
\hline Aceitação e publicação & 12 meses (média) & 13 meses (média) - de 7 a 19 meses \\
\hline Submissão e publicação & 18 meses (média) & 22 meses (média) - de 11 a 26 meses \\
\hline
\end{tabular}

Fonte: Elaborado pelos autores.

Fruto desses esforços, a importância da O\&S na comunidade não só tem se mantido como também aumentado. O fator de impacto calculado pela base de dados SPELL em 2016 sinaliza a inserção da O\&S entre as principais revistas do país no campo, após a RAE e a Revista de Administração Contemporânea (RAC), quando se analisa o indicador mais relevante, o fator de impacto relativo aos últimos 5 anos, sem considerar autocitações. Além dessa fonte de indicação de qualidade, a O\&S apareceu em 15 áreas do conhecimento no último quadriênio avaliado pela Capes (2013-2016). Assim, a revista se mostra importante para além do campo de Administração, tendo sido classificada, também, como Qualis A2 em História e Sociologia e Qualis B1 em Psicologia, Ciência Política, Interdisciplinar, Planejamento Urbano e Regional e Serviço Social.

A atual Editora, Professora Ariádne Scalfoni Rigo (desde 2016), aponta que, dentre as perspectivas e ações estratégias que vêm sendo pensadas e empreendidas para a O\&S, destacam-se: a solicitação de entrada em bases de dados importantes internacionais, como SCOPUS e EBSCO; a substantiva melhoria do site e dos elementos gráficos da revista; as progressivas reformulações de sua política e seu corpo editorial, que visam a atender às novas demandas de autores, avaliadores e leitores; os esforços para aumentar o fator de impacto por meio da publicação e divulgação de números em inglês, como forma de ampliar a leitura das contribuições dos pesquisadores que buscam a O\&S para uma audiência mais ampla. Esperamos que todas essas ações tendam a consolidar a O\&S no panteão das publicações nacionais na área de Administração.

Feitas essas considerações, e à guisa de conclusão, propomos uma pergunta a nós mesmos, muitas vezes, quando pensamos sobre o futuro da revista. Afinal, qual é "a cara" da O\&S? Não temos uma resposta definitiva, mas identificamos pistas. Uma delas deixada por um dos que assinam este artigo, quando de sua carta de despedida da edição da revista, no início de 2013. Naquela oportunidade, o Editor asseverou que a revista deve ser vista como heterodoxa, sem ser contra o mainstream.

Vida longa à O\&S!

Que a revista possa continuar sendo um exemplo de como é possível divulgar a produção científica do campo de Administração de modo consistente e qualificado, ainda que enfrentando desafios comuns aos periódicos vinculados às universidades públicas de nosso país. 


\section{REFERÊNCIAS}

FRANÇA FILHO, G. C. Apresentação. Organizações \& Sociedade, v. 3, n. 4, p. 5, 1995.

MOTTA, F. P. Organizações e Sociedade: a cultura brasileira. Organizações \& Sociedade, v. 7, n. 19, p. 13-17, 2000.

PINHO, J. A. G. Apresentação. Organizações \& Sociedade, v. 4, n. 7, p. 6, 1996.
PINHO, J. A. G. Homenagem da O\&S a Clóvis Machado-da-Silva. Organizações \& Sociedade, v. 17, n. 55, p. 747-748, 2010.

SERVA, M. Temporalidade, espaço e palavra. Organizações \& Sociedade, v. 1, n. 1, p. 27-41, 1993.

José Antonio Gomes de Pinho

Doutor em Regional Planning pela University of London (LSE); Professor Titular na Universidade Federal da Bahia (UFBA), Salvador - BA, Brasil. E-mail: jagp@ufba.br

Sandro Cabral

Doutor em Administração pela Universidade Federal da Bahia (UFBA); Professor Associado do Insper, São Paulo - SP, Brasil. Professor licenciado da Escola de Administração da Universidade Federal da Bahia (UFBA), Salvador - BA, Brasil. E-mail: sandroC2@insper.edu.br

Ariádne Scalfoni Rigo

Doutora em Administração pela Universidade Federal da Bahia (UFBA); Professora na Escola de Administração da Universidade Federal da Bahia (EAUFBA), Salvador-BA, Brasil. E-mail: ariadne.rigo@ufba.br 